\title{
Ventilatory and pulmonary vascular response to hypoxia and susceptibility to high altitude pulmonary oedema
}

\author{
E. Hohenhaus*, A. Paul*, R.E. McCullough**, H. Kücherer+, P. Bärtsch*
}

Ventilatory and pulmonary vascular response to hypoxia and susceptibility to high altitude pulmonary oedema. E. Hohenhaus, A. Paul, R.E. McCullough, H. Kücherer, P. Bärtsch. CERS Journals Ltd 1995.

ABSTRACT: Reduced tolerance to high altitude may be associated with a low ventilatory and an increased pulmonary vascular response to hypoxia. We therefore, examined whether individuals susceptible to acute mountain sickness (AMS) or high altitude pulmonary oedema (HAPE) could be identified by noninvasive measurements of these parameters at low altitude.

Ventilatory response to hypoxia (HVR) and hypercapnia (HCVR) at rest and during exercise, as well as hypoxic pulmonary vascular response (HPVR) at rest, were examined in 30 mountaineers whose susceptibility was known from previous identical exposures to high altitude.

Isocapnic HVR expressed as difference in minute ventilation related to difference in arterial oxygen saturation $\left(\Delta V^{\prime} \mathrm{E} / \Delta \mathrm{Sa}, \mathrm{O}_{2}\right)\left(\mathrm{L} \cdot \mathrm{min}^{-1 / \%}\right)$ was significantly lower in subjects susceptible to HAPE (mean \pm SEM $0.8 \pm 0.1 ; n=10$ ) compared to nonsusceptible controls $(1.5 \pm 0.2 ; n=10)$, but was not significantly different from subjects susceptible to AMS $(1.2 \pm 0.2 ; n=10)$. Hypercapnic ventilatory response was not significantly different between the three groups. Discrimination between groups could not be improved by measurements of HVR during exercise $(50 \%$ maximum oxygen consumption $\left(V^{\prime} \mathrm{O}_{2}\right.$, max $)$ ), or by assessing ventilation and oxygen saturation during a $15 \mathrm{~min}$ steady-state exercise $\left(35 \% \mathrm{~V}^{\prime} \mathrm{O}_{2}\right.$, $\left.\max \right)$ at fractional inspiratory oxygen $\left(F \mathrm{I}, \mathrm{O}_{2}\right)$ of 0.14. Pulmonary artery pressure $(P$ pa $)$ estimated by Doppler measurements of tricuspid valve pressure at an $F \mathrm{I}, \mathrm{O}_{2}$ of 0.21 and $0.12(10 \mathrm{~min})$ did not lead to a further discrimination between subjects susceptible to HAPE and AMS with the exception of three subjects susceptible to HAPE who showed an exaggerated HPVR.

It is concluded that a low ventilatory response to hypoxia is associated with an increased risk for high altitude pulmonary oedema, whilst susceptibility to acute mountain sickness may be associated with a high or low ventilatory response to hypoxia. A reliable discrimination between subjects susceptible to high altitude pulmonary oedema and acute mountain sickness with a low ventilatory response to hypoxia is not possible by Doppler echocardiographic estimations of hypoxic pulmonary vascular response.

Eur Respir J., 1995, 8, 1825-1833.
Depts of *Sports Medicine and +Cardiology, University of Heidelberg, Heidelberg, Germany. **Cardiovascular Pulmonary Research Laboratory, University of Colorado Health Sciences Center, Denver, CO, USA.

Correspondence: P. Bärtsch

Medizinische Universitätsklinik und Poliklinik

Abt. 1.7 Sport- und Leistungsmedizin

Hospitalstraße 3

D-69115 Heidelberg

Germany

Keywords: Acute mountain sickness doppler echocardiography

exercise

hypercapnic ventilatory response

hypoxic ventilatory response

pulmonary artery pressure

Received: March 131995

Accepted after revision June 221995

This study was supported by a grant from the Deutsche Forschungsgemeinschaft and by financial contributions of the Deutscher Alpenverein and the Bayer Company.
Rapid ascent to altitudes above 3,000 m may cause acute mountain sickness (AMS) [1], high altitude cerebral oedema (HACE) or high altitude pulmonary oedema (HAPE). In most cases, AMS resolves spontaneously, but it may progress to life-threatening HACE [2]. The relationship between AMS and the potentially lethal illness HAPE [3] remains obscure. The fact that administration of nifedipine during ascent can prevent HAPE [4] but not AMS [5], and the observation of several cases of HAPE which developed without preceding AMS, suggest that additional or specific factors are involved in the pathophysiology of HAPE compared with AMS. The degree of preacclimatization, the rate of ascent, and the altitude attained are important determinants for the occurrence of these illnesses. In addition, there are considerable interindividual differences regarding susceptibility to HAPE [4], and most likely also to AMS. It would, therefore, be desirable to be able to identify susceptible mountaineers by testing at low altitude.

A low hypoxic ventilatory response (HVR) has been suggested to be associated with susceptibility to AMS and HAPE. Several studies showed a significant association with AMS, or a history of AMS, and a low HVR [6-8], whilst other groups found no significant correlation $[9,10]$. Furthermore, a low HVR was reported during [11] and after recovery [12] from HAPE. There are, however, other investigators who found no relationship between HVR and a history of HAPE [13]. Taken together, 
the studies indicate that a low HVR is more frequent in susceptible subjects than in controls [13]. There is, however, a large overlap which does not allow the identification of susceptible mountaineers reliably by measuring HVR at low altitude.

The crucial role of a high pulmonary artery pressure in the pathophysiology of HAPE was demonstrated by the beneficial effects of drugs lowering pulmonary artery pressure for prevention and treatment of HAPE [4, 14-16]. An exaggerated hypoxic pulmonary vascular response (HPVR) was demonstrated at low altitude in mountaineers susceptible to HAPE by studies using cardiac catheterization [17-20]. However, there was also a considerable overlap in pulmonary artery pressure between susceptible subjects and controls [21], especially when Dopplerassessment was used [22].

Since the results of previous studies suggest that susceptibility to AMS may be associated with a low HVR and susceptibility to HAPE with a low HVR and an exaggerated HPVR, we hypothesized that discrimination between mountaineers nonsusceptible and susceptible to AMS or HAPE could be improved by combining measurements of ventilatory drives during rest and exercise with noninvasive measurements of HPVR by Doppler echocardiography. Therefore, we examined 30 subjects whose susceptibility was known from previous identical exposures to high altitude during participation in studies performed between 1986 and 1990 at 4,559 m, during which identical criteria for the diagnosis of AMS and HAPE had been applied.

\section{Methods}

\section{Subject and study design}

We studied 30 healthy male mountaineers whose susceptibility to acute mountain sickness and high altitude pulmonary oedema (10 control, 10 AMS, 10 HAPE) was known from previous identical exposures to high altitude. All were natives of low-altitude and were recruited from earlier studies performed at an altitude of 4,559 $\mathrm{m}$ between 1986 and 1990. During these studies, all subjects had ascended from 1,170 to $4,559 \mathrm{~m}$ within $24 \mathrm{~h}$, with an overnight stay at $3,611 \mathrm{~m}$. Symptoms of AMS were determined by the AMS-C score of the Environmental Symptom Questionnaire (ESQ) of SAMPSON et al. [23], and by the clinical score [4]. Subjects were considered not to be susceptible to AMS when their AMS-C score was $<0.7$ and the clinical score $<3$ in all examinations at high altitude. Susceptibility to AMS was assumed when the average scores obtained at $4,559 \mathrm{~m}$ over 2 or 3 days were $>1.0$ for AMS-C and $>3.0$ for the clinical score. Subjects were considered susceptible to HAPE when they had at least two radiographically documented episodes of HAPE, of which one had occurred during our high altitude studies.

The subjects were studied in Heidelberg, Germany, at an elevation of about $100 \mathrm{~m}$. None of the subjects had stayed at altitudes above 2,000 m during the last 2 weeks, or above $1,000 \mathrm{~m}$ during the last week before the study. The examination lasted 2 days. The examiners did not know the subject's susceptibility. On Day 1, maximum oxygen consumption and pulmonary function tests were measured. Doppler echocardiographic recordings were performed whilst breathing gases with different $\mathrm{O}_{2}$ concentrations. On Day 2, hypoxic and hypercapnic ventilatory responses were measured during rest and during exercise. Within the 2 day examination, the subjects were not allowed to smoke, to take any medication, to eat heavy food, or to drink beverages which could influence ventilation. The protocol for the study was approved by the Ethics Committee of the Medical Faculty of the University of Heidelberg, and the subjects gave their informed consent prior to the study.

\section{Measurement of maximal oxygen consumption}

The maximum oxygen consumption $\left(V^{\prime} \mathrm{O}_{2}, \max \right)$ was determined in order to quantitate the subject's fitness, and for further calculations of the exercise levels in the ventilatory tests. The subject had to perform a progressive exercise test on a bicycle ergometer, on which he was seated in a $45^{\circ}$ reclined position. This set-up was chosen since a reclined, semi-seated position was necessary for the ventilatory tests during exercise. Oxygen consumption was measured with an open ergospirometric system based on the breath-by-breath method (Oxycon Beta, Mijnhardt, Bunnik, The Netherlands) and related to the body weight. The highest $V^{\prime} \mathrm{O}_{2}$ average over a 1 min period was taken as $V^{\prime} \mathrm{O}_{2}$, max.

\section{Pulmonary function tests}

A body plethysmograph with spirometer (Universal Bodytest, Jaeger, Würzburg, Germany) was used for measurements of lung volumes and spirometry. The forced vital capacity (FVC), the forced expiratory volume in one second (FEV1), the expiratory flow rate at mid-point of vital capacity (MEF50\%) and the residual volume (RV) were measured and expressed per square metre of body surface area. Values of the best of three attempts are reported. In addition, the transfer factor was determined by the single-breath method; the volume of carbon monoxide $(T \mathrm{~L}, \mathrm{CO})$ transferred was related to the alveolar volume $(V \mathrm{~A})$.

\section{Measurement of hypoxic and hypercapnic ventilatory responses}

The ventilatory tests were performed in a quiet room at the same time of day in all subjects. The subject breathed through a low resistance respiratory valve from which expired minute ventilation $\left(V^{\prime} \mathrm{E}\right)$, end-tidal $\mathrm{O}_{2}$ tension $\left(P\right.$ ET, $\left.\mathrm{O}_{2}\right)$ and end-tidal $\mathrm{CO}_{2}$ tension $\left(P\right.$ ET, $\left.\mathrm{CO}_{2}\right)$ were measured by an open ergospirometric system based on the breath-by-breath method (Oxycon Beta, Mijnhardt, Bunnik, The Netherlands). In addition, arterial $\mathrm{O}_{2}$ saturation $\left(\mathrm{Sa}_{\mathrm{a}} \mathrm{O}_{2}\right)$ was continuously monitored by an 
oximeter using the finger probe (3740 Pulse Oximeter, Ohmeda Biox, Louiseville, USA). Each subject was familiarized with the ventilation system prior to the first measurement. For the tests performed at rest, the subject was seated comfortably in an armchair listening to calming music. All resting tests were performed twice and the mean value of the two measurements is reported. Measurements were repeated when the results of two trials differed by more than $25 \%$ of the higher response.

Hypoxic ventilatory response. The acute ventilatory response to isocapnic hypoxia was measured by inducing progressive hypoxia over 7-10 min while maintaining the $P$ ET, $\mathrm{CO}_{2}$ at the value observed during quiet breathing of room air. Progressive hypoxia was achieved by the gradual addition of nitrogen to a weather balloon containing $35 \% \mathrm{O}_{2}$. Isocapnia was obtained by adding $\mathrm{CO}_{2}$ to the inspired gas. During the test, the $P \mathrm{ET}, \mathrm{O}_{2}$ was reduced from approximately 21.3 to $5.3 \mathrm{kPa}$ (160 to 40 $\mathrm{mmHg}$ ). The test was stopped at an arterial oxygen saturation of $80 \%$. The acute ventilatory response to poikilocapnic hypoxia was measured following the same testing procedure as above, with the exception that no $\mathrm{CO}_{2}$ was added to the inspired air.

The hypoxic ventilatory response was analysed by relating $V^{\prime} \mathrm{E}$ either to $\mathrm{Sa}_{\mathrm{a}} \mathrm{O}_{2}$ or to $P \mathrm{ET}, \mathrm{O}_{2}$. The relationship of $V^{\prime} \mathrm{E}$ to $\mathrm{Sa}_{\mathrm{a}} \mathrm{O}_{2}$, which is considered to be linear [24], was analysed by fitting data to a linear equation: $V^{\prime} \mathrm{E}=\mathrm{b}$ $\left(S \mathrm{a}, \mathrm{O}_{2}\right.$ - intercept $)$; where $\mathrm{b}=\Delta V^{\prime} \mathrm{E} / \Delta S \mathrm{a}, \mathrm{O}_{2}$. The $\mathrm{Sa}_{\mathrm{a}} \mathrm{O}_{2}$ values on the abscissa were scaled from high to low in order to obtain a positive slope. The same scaling was applied for the plotting of $P$ ET, $\mathrm{O}_{2}$ versus $V^{\prime} \mathrm{E}$. The relationship of $V^{\prime} \mathrm{E}$ to $P \mathrm{ET}, \mathrm{O}_{2}$, which is considered to be hyperbolic [24], was analysed by fitting data to the hyperbolic equation: $V^{\prime} \mathrm{E}=V^{\prime} 0+\mathrm{A} /\left(P \mathrm{ET}, \mathrm{O}_{2}-32\right)$, where $A$ is the shape parameter [25]. $V^{\prime} 0$ is the asymptote for ventilation obtained by extrapolation, and 32 is the $\mathrm{Pa}, \mathrm{O}_{2}$ at which $V^{\prime}$ E approaches infinity. A-values were calculated using all data points between the beginning of the admixture of $\mathrm{N}_{2}$ and a $P$ ET, $\mathrm{O}_{2}$ which was reached by all subjects. This $P$ ET, $\mathrm{O}_{2}$ was $5.5 \mathrm{kPa}(41 \mathrm{mmHg})$ for the isocapnic HVR and $5.2 \mathrm{kPa}(39 \mathrm{mmHg})$ for the poikilocapnic HVR.

Hypercapnic ventilatory response. This was measured using a rebreathing technique [26]. The subject was connected to a closed breathing circuit initially containing $35 \% \mathrm{O}_{2}$. As the subject rebreathed, his $P$ ET, $\mathrm{CO}_{2}$ increased gradually. The test was stopped after 5-7 min when the $P$ ET, $\mathrm{CO}_{2}$ had risen by $1.3 \mathrm{kPa}(10 \mathrm{mmHg})$ over the initial value. The relationship between $V^{\prime} \mathrm{E}$ and $P \mathrm{ET}, \mathrm{CO}_{2}$, which is considered to be linear [26], was analysed by fitting data to the linear equation: $V^{\prime} \mathrm{E}=\mathrm{c}\left(P \mathrm{ET}, \mathrm{CO}_{2}-\right.$ intercept); where $\mathrm{c}=\Delta V^{\prime} \mathrm{E} / \Delta P \mathrm{ET}, \mathrm{CO}_{2}$.

Acute exercise ventilatory reponse. This was measured following the same testing procedure as during examinations at rest. In addition, the subject had to exercise on a bicycle ergometer with a workload corresponding to an $\mathrm{O}_{2}$ uptake of $50 \%$ of $V^{\prime} \mathrm{O}_{2}$, max determined on the previous day. Before measuring hypoxic responses, the subject had to exercise for $5 \mathrm{~min}$ at this workload whilst breathing room air. Calculations of the A-value were performed, including all data points until a $P$ ET, $\mathrm{O}_{2}$ of 6.7 $\mathrm{kPa}(50 \mathrm{mmHg})$ for the isocapnic HVR and $6.5 \mathrm{kPa}$ (49 $\mathrm{mmHg}$ ) for the poikilocapnic HVR.

A 15 min steady-state poikilocapnic hypoxic test was performed during exercise at a constant workload corresponding to $35 \%$ of $V^{\prime} \mathrm{O}_{2}$,max. After 5 min rest and 5 min exercise on room air, the subject breathed from a reservoir bag containing $14 \% \mathrm{O}_{2}$ in $\mathrm{N}_{2}$. No $\mathrm{CO}_{2}$ was added to the inspired air. Throughout the $15 \mathrm{~min}$ of hypoxia, $V^{\prime} \mathrm{E}$ and $\mathrm{Sa}_{\mathrm{a}} \mathrm{O}_{2}$ were measured and values were averaged over $1 \mathrm{~min}$ intervals. The ventilatory response was determined at 5,10 and $15 \mathrm{~min}$ by computing the increase in $V^{\prime} \mathrm{E}$ per reduction of $S_{\mathrm{a}, \mathrm{O}_{2}}\left(\Delta V^{\prime} \mathrm{E} / \Delta S_{\mathrm{a}}, \mathrm{O}_{2}\right)$ compared to baseline values (last minute of normoxic exercise). After 5,10 and $15 \mathrm{~min}, \mathrm{Sa}_{\mathrm{a}} \mathrm{O}_{2}$ was also measured in capillary blood obtained from a hyperaemic ear lobe on a CO-Oximeter 270 (Ciba Corning, Fernwald, Germany).

\section{Measurement of hypoxic pulmonary vascular responses}

Pulmonary vascular response to hypoxia was tested using Doppler echocardiography to estimate pulmonary artery pressure. After $30 \mathrm{~min}$ of rest in supine position, subjects were given a mask connected to a low resistance respiratory valve. The inspiratory side was connected to a reservoir bag which was alternately filled with three different humidified gases: $21 \% \mathrm{O}_{2}$ in $\mathrm{N}_{2}$; $14 \% \mathrm{O}_{2}$ in $\mathrm{N}_{2}$ and $12 \% \mathrm{O}_{2}$ in $\mathrm{N}_{2}$. Each gas was breathed for a period of $15 \mathrm{~min}$, with a $10 \mathrm{~min}$ rest on room air between each period. Doppler echocardiographic recordings were started in the 10th minute of each period. The order of the $\mathrm{O}_{2}$ concentrations was random, and unknown by both subject and examiner of the echocardiographic study. Doppler recordings were performed using a conventional ultrasound machine (Aloka SSD-870, PPG Hellige) and 2.5 MHz Duplex probes. In order to estimate systolic pulmonary artery pressure, peak flow velocities of tricuspid regurgitant jets were measured using continuous wave Doppler guided by two-dimensional echocardiography and colour flow Doppler. Gain settings were adjusted in each case to obtain tracings with adequate signal-to-noise ratio. The quality of Doppler tracings was regarded as adequate when a complete outline of the spectral waveform could be visually identified. In order to calculate the ratio between pulmonary artery flow velocity acceleration time (AT) and right ventricular ejection time (RVET) as another estimate of pulmonary artery pressure, flow velocity tracings of pulmonary artery blood flow were obtained just proximal to the pulmonary valve using pulsed wave Doppler. The recording obtained after $10 \mathrm{~min}$ at $21 \% \mathrm{O}_{2}$ was taken as baseline measurement. Data analysis was performed off-line independently, by the second observer who did not know from which subject a specific recording had been obtained or what $\mathrm{O}_{2}$ concentration was being breathed. The average values obtained from the analysis of three different cycles are reported. 
Table 1. - Characteristics and $\mathrm{VO}_{2}$, max of the study groups

\begin{tabular}{|c|c|c|c|c|}
\hline & Control & AMS & HAPE & p-value $\S$ \\
\hline Subjects $n$ & 10 & 10 & 10 & \\
\hline \multicolumn{5}{|l|}{ History } \\
\hline AMS-C score & $0.2 \pm 0.07$ & $1.7 \pm 0.2 * *$ & $1.58 \pm 0.4 * *$ & $<0.001$ \\
\hline Clinical score & $2.5 \pm 0.2$ & $5.8 \pm 0.4 * *$ & $5.4 \pm 0.7 * *$ & $<0.001$ \\
\hline Episodes of HAPE & 0 & 0 & $2.8(2-4)$ & $<0.001$ \\
\hline Age yrs & $40(26-56)$ & $39(29-52)$ & $41(28-55)$ & 0.83 \\
\hline $\mathrm{BMI} \mathrm{kg} \cdot \mathrm{m}^{-2}$ & $23.5 \pm 0.7$ & $23.9 \pm 0.53$ & $25 \pm 0.85$ & 0.29 \\
\hline$V^{\prime} \mathrm{O}_{2}, \max \mathrm{mL} \cdot \min ^{-1} \cdot \mathrm{kg}$ & $49.5 \pm 2.8$ & $48.4 \pm 2.7$ & $47.6 \pm 1.8$ & 0.76 \\
\hline
\end{tabular}

Scores are taken from preceding studies. Values are presented as mean \pm SEM. Figures in parentheses are ranges. BMI: body mass index; $V^{\prime} \mathrm{O}_{2}$,max: maximal oxygen consumption; AMS: acute mountain sickness; HAPE: high altitude pulmonary oedema; AMS-C score: of the Environmental Symptom Questionnaire (ESQ). §: p-value refers to Kruskal-Wallis test; **: p<0.01, compared to the control group (Nemenyi test).

Table 2. - Pulmonary function data

\begin{tabular}{lcccc}
\hline & Control & AMS & HAPE & p-value $\S$ \\
\hline Subjects n & 10 & 10 & 10 & \\
FVC L $\cdot m^{-2}$ & $2.99 \pm 0.11$ & $2.86 \pm 0.09$ & $2.72 \pm 0.1$ & 0.11 \\
TLC L $\cdot \mathrm{m}^{-2}$ & $4.25 \pm 0.12$ & $3.88 \pm 0.14$ & $3.78 \pm 0.13$ & 0.06 \\
FEV $/ \mathrm{FVC} \%$ & $75 \pm 2$ & $81 \pm 2$ & $80 \pm 2$ & 0.08 \\
MEF50\% L $\cdot \mathrm{s}^{-1} \cdot \mathrm{m}^{2}$ & $2.48 \pm 0.32$ & $2.94 \pm 0.24$ & $2.73 \pm 0.25$ & 0.42 \\
KCO $\mathrm{mmol} \cdot \mathrm{s}^{-1} \cdot \mathrm{kPa}^{-1} \cdot \mathrm{L}^{-1}$ & $0.028 \pm 0.001$ & $0.030 \pm 0.001$ & $0.034 \pm 0.001 *$ & $<0.025$ \\
\hline
\end{tabular}

Data are presented as mean \pm SEM. Measurements reported are in body temperature, atmospheric pressure and saturation with water vapour (BTPS) values. §: p-value refers to Kruskal-Wallis test; *: p<0.05, compared to control group (Nemenyi test). FVC: forced vital capacity; TLC: total lung capacity; FEV1: forced expiratory volume in one second; MEF50\%: flow rate at mid-point of vital capacity; Kco: transfer factor for carbon monoxide related to the alveolar volume. For further abbreviations see legend to table 1

The right ventricular to right atrial tricuspid pressure (TP) gradient was calculated from the maximum velocity (V) within the trancuspid jet of at least three beats, using a modified Bernoulli equation: $\mathrm{TP}=4 \mathrm{~V}^{2}$ [27]. In 22 examinations involving nine subjects, pressure gradients could not be calculated, because of insufficient Doppler spectra in six and absent tricuspid regurgitation in three subjects. AT represents the interval from the opening snap of the pulmonary valve to peak velocity [28], and RVET was measured as the time from onset to end of the pulmonary flow velocity tracing.

\section{Statistical analysis}

Differences between groups were compared by nonparametric analysis of variance (Kruskal Wallis) and Nemenyi test for post-hoc testing. Two-sided p-values are reported. Relationships between variables are examined by linear regression. Multiple logistic regression was performed for HAPE versus non-HAPE susceptibles (AMS and control group together), including various combinations of two parameters of ventilatory responses at exercise or rest, of Doppler echocardiographic measurements and of oxygen saturation during exercise. Values are given as means \pm SEM.

\section{Results}

The characteristics of the study groups are presented in table 1. The AMS-C and the clinical score did not differ significantly between the AMS and HAPE group. Subjects of the latter group had experienced 2-4 episodes of radiographically documented HAPE. Age, body mass index, and maximal oxygen consumption were similar in the study groups. All subjects showed similar spirometric data within normal limits (table 2). There was, however, a tendency to lower FEV1 values and higher lung volumes in control subjects compared with the other groups. A comparison between control and HAPE-susceptible subjects revealed a significantly lower total lung capacity in the latter group ( $\mathrm{p}=0.04$; Mann-Whitney Utest). Transfer factor at rest expressed as $T \mathrm{~L}, \mathrm{CO} / \mathrm{VA}$ (Kco) was highest in the HAPE group.

Ventilatory responses at rest are presented in table 3. Isocapnic HVR expressed as $\Delta V^{\prime} \mathrm{E} / \Delta \mathrm{Sa}, \mathrm{O}_{2}$ was significantly lower in the HAPE compared to the control group. Individual values are shown in figure 1. They demonstrate that there was little overlap between the HAPE and control group whilst values of the AMS group showed a large scatter. Isocapnic HVR expressed as A-value was also significantly lower in the HAPE than in the control group. However, overlap of individual results between these groups (data not shown) was considerably more pronounced than with isocapnic HVR expressed as $\Delta V^{\prime} \mathrm{E} / \Delta S \mathrm{a}, \mathrm{O}_{2}$. Poikilocapnic $\mathrm{HVR}$ expressed as $\Delta V^{\prime} \mathrm{E} / \Delta S \mathrm{Sa}, \mathrm{O}_{2}$ or as A-value and HCVR were not significantly different between groups.

Ventilatory responses during exercise are presented in table 4. Poikilocapnic and isocapnic HVR increased twoto three fold above resting values when expressed as $\Delta V^{\prime} \mathrm{E} / \Delta \mathrm{Sa}, \mathrm{O}_{2}$ and four- to seven fold when expressed as A-values. Differences between groups were comparable with the measurements at rest, revealing significantly lower values for the HAPE compared with the control group. There was, however, considerable overlap of 


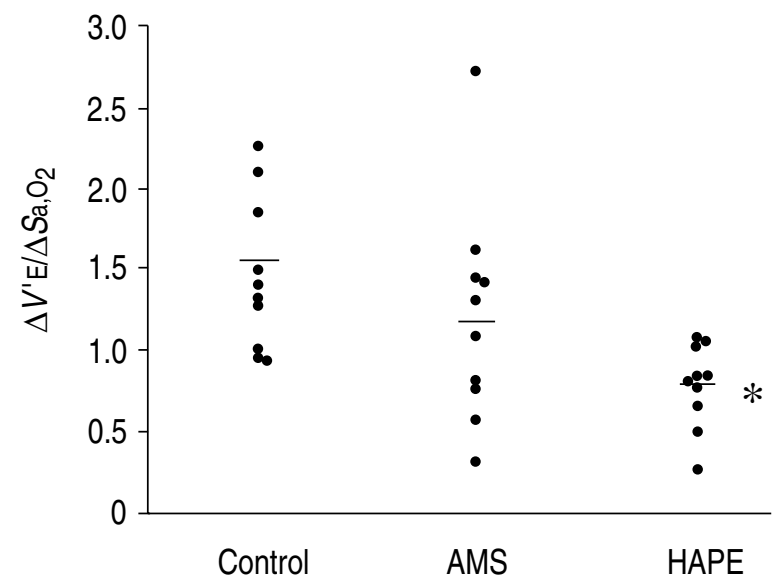

Fig. 1. - Individual (•) and mean (一) values of acute hypoxic ventilatory response $\left(\Delta V^{\prime} \mathrm{E} / \Delta S_{\mathrm{a}, \mathrm{O}_{2}}\right)$ during isocapnia at rest. ${ }^{*}: \mathrm{p}<0.01$ for the changes of $\Delta V^{\prime} \mathrm{E} / \Delta S_{\mathrm{a}, \mathrm{O}_{2}}$ from the control group. $\Delta V^{\prime} \mathrm{E} / \Delta S_{\mathrm{a}, \mathrm{O}_{2}}$ : increase in minute ventilation per percentage reduction in arterial oxygen saturation; AMS: acute mountain sickness; HAPE: high altitude pulmonary oedema.

individual values among all groups. HCVR during exercise was similar between groups and significantly higher compared with measurements at rest in all groups $(\mathrm{p}<0.005$ for each group; Wilcoxon test).

The steady-state exercise test $\left(35 \% V^{\prime} \mathrm{O}_{2}\right.$, max $)$ at a fractional inspiratory oxygen $\left(F \mathrm{I}, \mathrm{O}_{2}\right)$ level of 0.14 revealed no significant differences among groups after 5, 10 and 15 min duration. $\mathrm{Sa}, \mathrm{O}_{2}$ measured in arterialized capillary blood fell to $81 \pm 2 \%$ in the control, $80 \pm 1 \%$ in the AMS and $79 \pm 2 \%$ in the HAPE group after $15 \mathrm{~min}$. The corresponding increase of ventilation was $0.36 \pm 0.06,0.34 \pm 0.04$ and $0.31 \pm 0.03 \mathrm{~L} \cdot \mathrm{min}^{-1} / \% \mathrm{Sa}_{2} \mathrm{O}_{2}$, respectively.

The pulmonary vascular response to hypoxia is shown in table 5 and figure 2. Due to insufficient Doppler spectra or absent tricuspid regurgitation, the pressure gradient at the tricuspid valve (TP) could not be assessed in nine subjects. The increase of TP was not significantly different among groups at either level of hypoxia. There was, however, a consistent trend toward lowest values in the AMS group and highest values in the HAPE group. Individual and mean values of $\mathrm{TP}$ at an $\mathrm{FI}, \mathrm{O}_{2}$ of 0.21 and 0.12 are shown in figure 2. Mean values increased significantly in the HAPE and control group, and mean $\mathrm{TP}$ at an $F \mathrm{I}, \mathrm{O}_{2}$ of 0.12 was significantly higher in the HAPE compared with the AMS group. Only three of eight HAPE-susceptible subjects, however, showed an exaggerated rise in pulmonary artery pressure.

The mean values obtained for AT/RVET revealed a similar pattern to TP measurements (table 5, and fig. 2 ). Individual values shown in figure 2 demonstrate that there was an unexpected considerable increase of AT/ RVET at an $F \mathrm{I}_{2} \mathrm{O}_{2}$ of 0.12 in five subjects of the AMS group, leading to a small increase of the mean values of this group. AT/RVET also increased in three and two

Table 3. - Acute hypoxic and hypercapnic responses during rest

\begin{tabular}{|c|c|c|c|c|}
\hline & Control & AMS & HAPE & p-value $\S$ \\
\hline $\begin{array}{l}\text { Subjects } \mathrm{n} \\
\text { HVR isocapnic }\end{array}$ & 10 & 10 & 10 & \\
\hline$\Delta V^{\prime} \mathrm{E} / \Delta S_{\mathrm{a}, \mathrm{O}_{2}} \quad \mathrm{~L} \cdot \mathrm{min}^{-1} / \%$ & $1.5 \pm 0.2$ & $1.2 \pm 0.2$ & $0.8 \pm 0.1 * *$ & $<0.01$ \\
\hline $\begin{array}{l}\text { A-value } \\
\text { HVR poikilocapnic }\end{array}$ & $255 \pm 28$ & $210 \pm 43$ & $145 \pm 15^{*}$ & 0.05 \\
\hline $\begin{array}{l}\Delta V^{\prime} \mathrm{E} / \Delta S_{\mathrm{a}, \mathrm{O}_{2}} \quad \mathrm{~L} \cdot \mathrm{min}^{-1} / \% \\
\text { A-value }\end{array}$ & $\begin{array}{c}0.7 \pm 0.1 \\
105 \pm 17\end{array}$ & $\begin{array}{c}0.6 \pm 0.1 \\
88 \pm 15\end{array}$ & $\begin{array}{l}0.4 \pm 0.1 \\
73 \pm 6\end{array}$ & $\begin{array}{l}0.16 \\
0.30\end{array}$ \\
\hline $\begin{array}{l}\text { HCVR } \\
\Delta V^{\prime} \mathrm{E} / \Delta P \mathrm{ET}, \mathrm{CO}_{2} \mathrm{~L} \cdot \mathrm{min}^{-1} \cdot \mathrm{mmHg}^{-1}\end{array}$ & $2.3 \pm 0.2$ & $1.9 \pm 0.2$ & $1.9 \pm 0.3$ & 0.30 \\
\hline
\end{tabular}

Data are presented as mean \pm SEM. $\S$ : p-value refers to Kruskal-Wallis test; *: $\mathrm{p}<0.05 ; * *$ : $\mathrm{p}<0.01$ for the comparison of changes from the control group (Nemenyi test). $\Delta V^{\prime} \mathrm{E} / \Delta S_{\mathrm{a}, \mathrm{O}_{2}}$ : increase in minute ventilation per percentage reduction in arterial oxygen saturation; $\Delta V^{\prime} \mathrm{E} / \Delta P \mathrm{ET}, \mathrm{CO}_{2}$ : increase in minute ventilation related to end-tidal carbon dioxide tension; HVR: hypoxic ventilatory response; HCVR: hypercapnic ventilatory response; A: shape parameter of the hyperbolic equation $V^{\prime} \mathrm{E}=V^{\prime} 0+\mathrm{A} /\left(P_{\mathrm{ET}}, \mathrm{O}_{2}-32\right)$, thus the higher the A-value the greater the ventilatory response to hypoxia. For further abbreviations see legend to table 1.

Table 4. - Acute hypoxic and hypercapnic responses during exercise

\begin{tabular}{|c|c|c|c|c|}
\hline & Control & AMS & HAPE & p-value $\S$ \\
\hline Subjects $\mathrm{n}$ & 10 & 10 & 10 & \\
\hline \multicolumn{5}{|l|}{ HVR isocapnic } \\
\hline$\Delta V^{\prime} \mathrm{E} / \Delta S_{\mathrm{a}, \mathrm{O}_{2}} \quad \mathrm{~L} \cdot \mathrm{min}^{-1} / \%$ & $3.1 \pm 0.3$ & $2.8 \pm 0.4$ & $1.9 \pm 0.1 * *$ & $<0.025$ \\
\hline A-value & $1093 \pm 114$ & $946 \pm 87$ & $756 \pm 64 *$ & 0.05 \\
\hline \multicolumn{5}{|l|}{ HVR poikilocapnic } \\
\hline$\Delta V^{\prime} \mathrm{E} / \Delta S_{\mathrm{a}, \mathrm{O}_{2}} \quad \mathrm{~L} \cdot \mathrm{min}^{-1} / \%$ & $2.1 \pm 0.2$ & $1.7 \pm 0.2$ & $1.4 \pm 0.1 * *$ & 0.01 \\
\hline A-value & $752 \pm 57$ & $608 \pm 71$ & $520 \pm 25^{*}$ & $<0.05$ \\
\hline \multicolumn{5}{|l|}{ HCVR } \\
\hline$\Delta V^{\prime} \mathrm{E} / \Delta P \mathrm{ET}, \mathrm{CO}_{2} \mathrm{~L} \cdot \mathrm{min}^{-1} \cdot \mathrm{mmHg}^{-1}$ & $3.8 \pm 0.4$ & $3.4 \pm 0.5$ & $3.1 \pm 0.3$ & 0.36 \\
\hline
\end{tabular}

Values are presented as mean \pm SEM. $\S:$-values refers to Kruskal-Wallis test; $*$ : $<<0.05 ; * *: p<0.01$ for the comparison of changes from the control group (Nemenyi test). For abbreviations see legends to tables 1 and 3. 


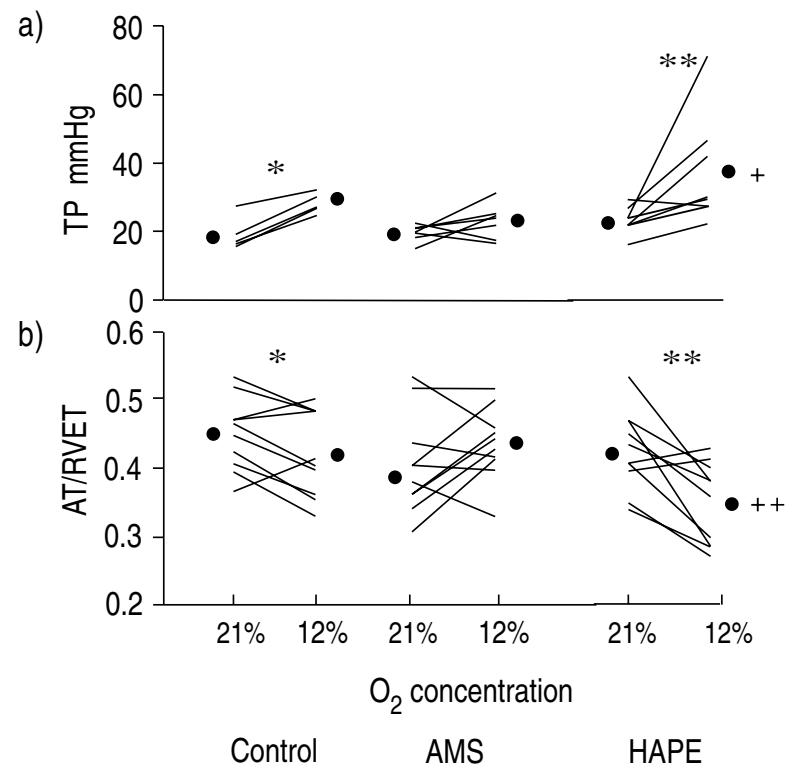

Fig. 2. - Individual values and mean values (•) of a) the pressure gradient at the tricuspid valve (TP) and; b) the changes for the acceleration time expressed as a fraction of the total ejection time in the main pulmonary artery (AT/RVET) of each study group at an $F_{\mathrm{I}, \mathrm{O}_{2}}$ of 0.21 and $0.12 ; F_{\mathrm{I}, \mathrm{O}_{2}}$ : fractional inspiratory oxygen value. For further abbreviations see legend to figure 1 . *: $\mathrm{p}<0.05$, and **: $\mathrm{p}<0.025$ for comparison within a particular group (Wilcoxon test); $+: \mathrm{p}<0.05$, and ++: $\mathrm{p}<0.025$ compared to AMS group for values measured at $F_{\mathrm{I}, \mathrm{O}_{2}}=0.12$ (Kruskal-Wallis and Nemenyi test).

subjects of the control and HAPE group, respectively. In most cases, however, the increases of AT/RVET were not accompanied by a decrease of TP. Therefore, we found no significant correlation $(\mathrm{r}=0.23 ; \mathrm{p}=0.053)$ between the two parameters considering the values of all measurements $(n=69)$, nor between the decrease of AT/RVET and the increase in TP when going from 21 to $12 \% \mathrm{O}_{2}$ $(\mathrm{r}=0.16 ; \mathrm{p}=0.49 ; \mathrm{n}=21)$.

Changes of TP and ET/RVET obtained at an $\mathrm{F}_{\mathrm{I}, \mathrm{O}_{2}}$ of 0.14 compared to those obtained at an $F_{\mathrm{I}, \mathrm{O}_{2}}$ of 0.12 were less pronounced, especially in the HAPE group, and resulted in smaller differences between groups (table 5). At both levels of hypoxia there was a statistically nonsignificant trend towards lower oxygen saturation in the HAPE compared to the control group and to the AMS group at $\mathrm{F}_{\mathrm{I}, \mathrm{O}_{2}}=0.12$. Furthermore, there was a significant correlation between $\mathrm{Sa}_{\mathrm{a}} \mathrm{O}_{2}$ and the pressure gradient at $F \mathrm{I}, \mathrm{O}_{2}=0.12(\mathrm{r}=0.67 ; \mathrm{p}=0.001)$. No significant correlation was observed between $\mathrm{Sa}_{\mathrm{a}} \mathrm{O}_{2}$ and hypoxiainduced changes of AT/RVET.

\section{Discussion}

Among a group of mountaineers who had been identically exposed to high altitude prior to this investigation, we found that susceptibility to HAPE is associated with a low HVR, which shows little overlap of individual values with those obtained in mountaineers with a good tolerance to high altitude. High HVR values were not observed in HAPE-susceptible subjects in our study, and exaggerated HPVR assessed by Doppler echo-cardiography occurred only in this group. A large variability in HVR was found in subjects with a history of AMS. Therefore, we conclude that a low HVR indicates an increased risk for the development of AMS or HAPE, whilst a normal or high HVR does not exclude susceptibility to AMS but indicates a low risk for the development of HAPE. An exaggerated HPVR, especially in combination with a low HVR, is likely to be a reliable marker for susceptibility to HAPE.

In subjects with a low HVR it was not possible to discriminate reliably between AMS and HAPE-susceptibles by Doppler echocardiographic estimation of the pressure gradient at the tricuspid valve (TP) with the exception of three subjects with an exaggerated response (fig. 3 ). The lack of sufficient discrimination may, in part, be attributed to the limitations associated with this noninvasive measurement for detecting small differences of

Table 5. - Pulmonary vascular responses to hypoxia

\begin{tabular}{|c|c|c|c|c|}
\hline & Control & AMS & HAPE & p-value $\S$ \\
\hline \multicolumn{5}{|l|}{$\overline{\Delta T P} \mathbf{m m H g}$} \\
\hline $0.14 F \mathrm{I}, \mathrm{O}_{2}$ & $\begin{array}{c}6.6 \pm 1.81 \\
(\mathrm{n}=7)\end{array}$ & $\begin{array}{c}4.3 \pm 1.4 \\
(n=8)\end{array}$ & $\begin{array}{c}4.3 \pm 2.2 \\
(n=8)\end{array}$ & 0.52 \\
\hline $0.12 F \mathrm{I}, \mathrm{O}_{2}$ & $\begin{array}{c}9.2 \pm 1.0 \\
(\mathrm{n}=6)\end{array}$ & $\begin{array}{c}3.3 \pm 2.2 \\
(\mathrm{n}=7)\end{array}$ & $\begin{array}{c}13.7 \pm 5.5 \\
(\mathrm{n}=8)\end{array}$ & 0.08 \\
\hline \multicolumn{5}{|l|}{$\Delta$ AT/RVET } \\
\hline $0.14 F \mathrm{I}, \mathrm{O}_{2}$ & $\begin{array}{c}-0.04 \pm 0.01 \\
(n=10)\end{array}$ & $\begin{array}{c}0.02 \pm 0.03 \\
(n=10)\end{array}$ & $\begin{array}{c}-0.02 \pm 0.03 \\
(n=10)\end{array}$ & 0.12 \\
\hline $0.12 F \mathrm{I}, \mathrm{O}_{2}$ & $\begin{array}{c}-0.03 \pm 0.01 \\
(n=10)\end{array}$ & $\begin{array}{c}0.03 \pm 0.02 \\
\quad(\mathrm{n}=10)\end{array}$ & $\begin{array}{c}-0.07 \pm 0.02 * * \\
(\mathrm{n}=10)\end{array}$ & $<0.01$ \\
\hline \multicolumn{5}{|l|}{$\mathrm{S}_{\mathrm{a}, \mathrm{O}_{2}} \%$} \\
\hline $0.14 F \mathrm{I}, \mathrm{O}_{2}$ & $\begin{array}{c}89.3 \pm 0.6 \\
(n=10)\end{array}$ & $\begin{array}{c}87.6 \pm 0.8 \\
(n=10)\end{array}$ & $\begin{array}{c}88.6 \pm 0.5 \\
(n=10)\end{array}$ & 0.13 \\
\hline $0.12 F_{\mathrm{I}, \mathrm{O}_{2}}$ & $\begin{array}{c}82.3 \pm 1.3 \\
(\mathrm{n}=10)\end{array}$ & $\begin{array}{c}80.2 \pm 1.0 \\
(\mathrm{n}=10)\end{array}$ & $\begin{array}{c}77.9 \pm 1.3 \\
(\mathrm{n}=10)\end{array}$ & 0.11 \\
\hline
\end{tabular}

Values are presented as mean \pm SEM. Figures in parenthesis represent number of subjects. TP: pressure gradient at tricuspid valve; AT/RVET: acceleration time in pulmonary artery expressed as fraction of the right ventricular ejection time; $\mathrm{S}_{\mathrm{a}, \mathrm{O}_{2}}$ : arterial oxygen saturation; $\mathrm{FI}, \mathrm{O}_{2}$ : fractional inspiratory oxygen; $\Delta$-values represent the data measured at 14 and $12 \%$ respectively, $F \mathrm{I}, \mathrm{O}_{2}$, minus data measured at $21 \% \quad F \mathrm{I}_{2} \mathrm{O}_{2} . \quad \S$ : p-value refers to Kruskal-Wallis test; **: $\mathrm{p}<0.001$, compared to the AMS group (Nemenyi test). For further abbreviations see legend to table 1. 
pulmonary artery pressure, which were in the order of $0.7-1.3 \mathrm{kPa}(5-10 \mathrm{mmHg})$ among subjects of comparable previous invasive studies [18-20]. Further limitation of Doppler echocardiographic measurements, especially with regard to TP, may be associated with the skills of the examiner, the type of equipment used, and the fact that regurgitation jets cannot always be recovered. The examiner involved in this study was a cardiologist with long-standing experience in echocardiography, and his recovery rate of regurgitation jets $(75 \%)$ was comparable to that of other investigators $[4,22]$. Thus, we exclude the possibility that particular factors restricted to the present study have caused the negative finding regarding reliable identification of HAPE-susceptible subjects.

Although the changes of AT/RVET appear to discriminate better than TP measurements between AMS and HAPE-susceptibles (fig. 3), we hesitate to accept these values as a reflection of changes in pulmonary artery pressure, because the improved separation is due mainly to an increase of AT/RVET in several subjects of the AMS group, suggesting a decrease of pulmonary artery pressure under hypoxia in these subjects. This is, however, very unlikely to have occurred, and is not supported by estimations based on tricuspid regurgitation jets of our study (fig. 2) and invasive measurements reported in comparable studies [18-21]. Our unexpected findings may be explained by a larger variability of the

a)

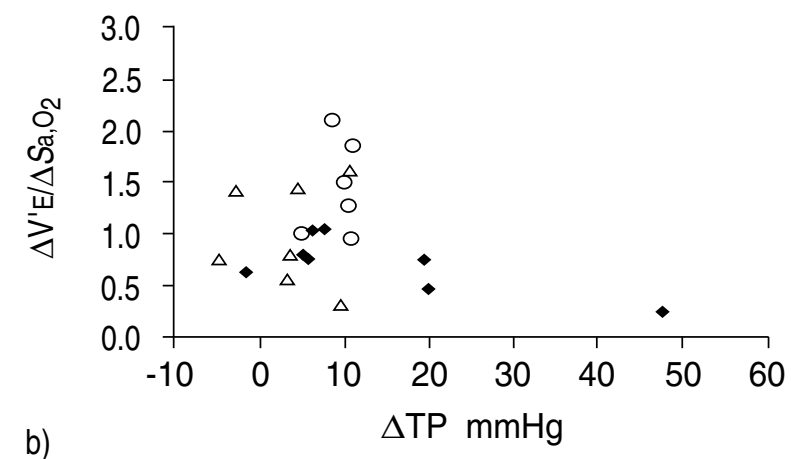

b)

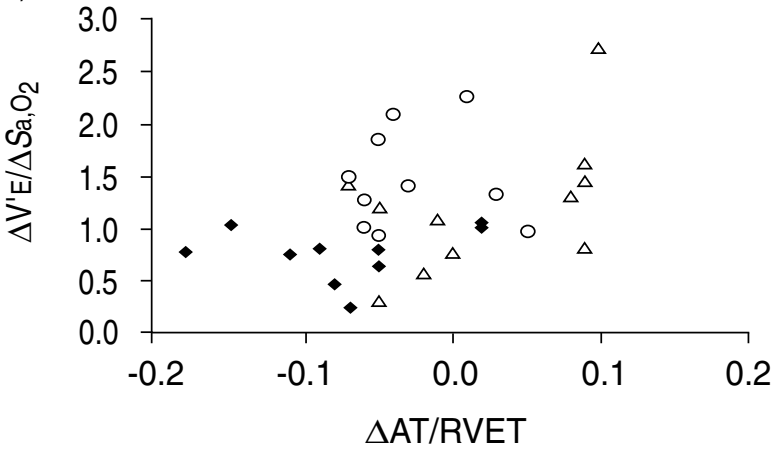

Fig. 3. - Individual values of the isocapnic HVR plotted against the HPVR. HVR is expressed as $\Delta \mathrm{V}^{\prime} \mathrm{E} / \mathrm{Sa}_{\mathrm{a}} \mathrm{O}_{2}$. HPVR is expressed as: a) the changes of the pressure gradient at the tricuspid valve (TP) and; b) the changes in the acceleration time expressed as a fraction of the total ejection time in the main pulmonary artery (AT/RVET) when breathing air containing $12 \%$ compared with $21 \% \mathrm{O}_{2}$. HVR: hypoxic ventilatory response; HPVR: hypoxic pulmonary vascular response. For further abbreviations see legend to figure 1. O: control; $\bullet$ : HAPE; $\Delta$ : AMS assessment of AT/RVET compared with tricuspid regurgitation jets [29], possibly due to sampling errors, the small changes in pulmonary artery pressure in the order of $0.7-2.0 \mathrm{kPa}(5-15 \mathrm{mmHg})$, and the fact that we carefully eliminated possible examiner bias since the examiner and the subject did not know which gas was supplied. Furthermore, the history of the subject was not known to the examiner and an independent investigator analysed the tapes off-line.

The lack of discrimination between AMS and HAPEsusceptible subjects with a low HVR may not only be attributed to an insufficient ratio of the variability of the method to the size of the effect. It is conceivable that additional, unknown factors associated with susceptibility to HAPE must be considered, or else that a short exposure lasting $10 \mathrm{~min}$ at an $\mathrm{F} \mathrm{I}_{\mathrm{O}} \mathrm{O}_{2}$ of $0.12-0.14$ may not give rise to the full HPVR which occurs during exposure at high altitude.

The low HVR of HAPE-susceptible mountaineers confirms the results of two previous studies measuring poikilocapnic HVR during HAPE [11], and isocapnic HVR in mountaineers with a history of HAPE [12], both expressed as $\Delta V^{\prime} \mathrm{E} / \Delta S \mathrm{~S}, \mathrm{O}_{2}$. We found only minimal overlap between healthy controls and HAPE-susceptible mountaineers, in contrast to a previous investigation in which acclimatized mountaineers [11] or subjects with self-reported good tolerance to high altitude [12] were used as controls. Our data indicate that this overlap may be minimized when tolerance to high altitude is evaluated under more standardized conditions. Mountaineers who could ascend to $4,559 \mathrm{~m}$ within $24 \mathrm{~h}$ without getting AMS as defined by our criteria all had an HVR $>1$ $\mathrm{L} \cdot \mathrm{min}^{-1} / \% \mathrm{Sa}_{\mathrm{a}} \mathrm{O}_{2}$. None of our HAPE susceptible subjects had an $\mathrm{HVR}>1 \mathrm{~L} \cdot \mathrm{min}^{-1} / \% \mathrm{Sa}_{\mathrm{a}} \mathrm{O}_{2}$ or an A-value over 200. It was recently reported that three of four mountaineers with a history suggesting HAPE had Avalues between 200 and 400 [13]. However, susceptibility to HAPE was less certain in this investigation compared to the present study in which all susceptible subjects had at least two episodes of radiographically documented HAPE. Nevertheless, a high HVR may not necessarily protect from HAPE. HPVR, which was not measured in the subjects of SELLAND et al. [13], must also be considered as a possible independent risk factor. On the other hand, the correlation between the increase of pulmonary artery pressure at $12 \% \mathrm{O}_{2}$ and $\mathrm{Sa}_{\mathrm{a}} \mathrm{O}_{2}$ observed in the present study suggest that a low HVR may contribute to an increase of HPVR by enhancing alveolar hypoxia, the primary stimulus for hypoxic vasoconstriction of pulmonary arterioles.

The wide scatter of HVR in the AMS group is in agreement with the results of previous studies which used comparable methods of assessing $\operatorname{HVR}[9,10,30]$, and which found no association between this measurement at low altitude and the occurrence of AMS during exposure to high altitude. Of three studies reporting a significant negative association between HVR and AMS, two used different methods [7, 8], and the third found, in a small group of 12 subjects (eight susceptibles and four controls), significant differences in the poikilocapnic but not the isocapnic response between the AMS 
and the control group [6]. The latter study suggests, however, that hypoxic depression of ventilation may be associated with AMS. Indeed, direct or indirect measurements of ventilation performed at real or simulated altitude suggest hypoventilation of subjects with AMS compared with controls $[5,6,8,10,31]$. These observations could be explained by differences in hypoxic depression of ventilation or else by changes of the HVR occurring at high altitude. In summary, several studies, including the present investigation, have demonstrated that susceptibility to AMS cannot be predicted by measuring HVR at low altitude.

In agreement with previous investigations $[6,9,30]$ we found no significant differences of HCVR between mountaineers nonsusceptible and susceptible to HAPE or AMS. Furthermore, pulmonary function tests revealed no significant differences between the three groups. Although measurements of HAPE-susceptible subjects prior to the first episode of HAPE are not available, our data indicate that repeated episodes of HAPE do not lead to persistent pulmonary dysfunction detectable at rest. Interestingly, HAPE-susceptible subjects have lower lung volumes than controls. Comparable results have been reported by other investigators ([20]; personal communication by $\mathrm{P}$. Wagner). Thus, it is conceivable that a presumably smaller vascular capacity due to smaller lung volumes may contribute to higher pulmonary artery pressures, especially during exercise.

The exercise tests did not discriminate better between groups. Both HVR and HCVR were increased with exercise but showed a similar pattern to the measurements performed at rest. Individual values showed a slightly greater overlap compared to resting values. In contrast to a previous study, we found no significant differences between groups in the decrease of $\mathrm{Sa}_{2} \mathrm{O}_{2}$ and the increase of ventilation during a steady-state exercise over $15 \mathrm{~min}$ [32]. The discrepancy may be due to a lower level of exercise intensity (35 vs, 50\% $\mathrm{V}^{\prime} \mathrm{O}_{2}$, max) and hypoxia (14 vs 11.5\%) which were chosen for reasons of safety.

Multiple logistic regression, including parameters of ventilatory response at rest or exercise, echocardiographic data and/or oxygen saturation during exercise, did not lead to a statistically significant model for prediction of susceptibility to HAPE, except for the combination of AT/RVET and isocapnic HVR which is presented in figure 3b. As stated above, AT/RVET does not appear to have given a reliable estimation of HPVR in this study; Therefore, we do not report the regression equation of this model.

This investigation demonstrates that susceptibility to AMS and HAPE cannot be reliably identified by measurements of HVR at rest or exercise and Doppler echocardiographic estimation of HPVR, although a low HVR appears to predispose to these conditions. It is possible that discrimination could be improved by direct measurements of pulmonary artery pressure possibly during more severe and prolonged hypoxic exposure. However, such a procedure would not be applicable for clinical use because it is invasive and it would lead to levels of hypoxaemia below $80 \% \mathrm{Sa}_{2} \mathrm{O}_{2}$, considered as the safety limit in this study.
Acknowledgements: The authors gratefully acknowledge the support of the Cardiovascular Pulmonary Research Laboratory, Denver, CO, USA (J.V. Weil, J.T. Reeves, RE. and RG. McCullough) for introducing the measurement of ventilatory drives. Furthermore, they are indebted to C. Lehmann (Department of Sports Medicine, Heidelberg, Germany) for her excellent technical assistance and to U. Waibel (Department for Cardiology, Heidelberg, Germany) for performing the pulmonary function tests.

\section{References}

1. Johnson TS, Rock PB. Acute mountain sickness. $N$ Engl J Med 1988; 319: 841-845.

2. Houston CS, Dickinson J. Cerebral form of high-altitude illness. Lancet 1975; ii: 758-761.

3. Houston CS. Acute pulmonary edema of high altitude. N Engl J Med 1960; 263: 478-480.

4. Bärtsch P, Maggiormi M, Ritter M, Noti C, Vock P, Oelz O. Prevention of high-altitude pulmonary edema by nifedipine. N Engl J Med 1991; 325: 1284-1289.

5. Hohenhaus E, Niroomand F, Goerre S, Vock P, Oelz O, Bärtsch P. Nifedipine does not prevent acute mountain sickness. Am J Respir Crit Care Med 1994; 150: 857860.

6. Moore LG, Hamson GL, McCullough RE, et al. Low acute hypoxic ventilatory response and hypoxic depression in acute altitude sickness. J Appl Physiol 1986; 60: 1407-1412.

7. Hu ST, Huang SY, Chu SC, Pa CF. Chemoreflexive ventilatory response at sea level in subjects with past history of good acclimatization and severe acute mountain sickness. In: Brendel W, Zink RA, eds. High Altitude Physiology and Medicine. New York; Springer-Verlag, 1982; pp. 28-33.

8. King AB, Robinson SM. Ventilation response to hypoxia and acute mountain sickness. Aerosp Med 1972; 43: 419-421.

9. Milledge JS, Beeley JM, Broome J, Luff N, Pelling M, Smith D. Acute mountain sickness susceptibility, fitness and hypoxic ventilatory response. Eur Respir J 1991; 4: 1000-1003.

10. Sutton JR, Bryan AC, Gray GW, et al. Pulmonary gas exchange in acute mountain sickness. Aviat Space Environ Med 1976; 47: 1032-1037.

11. Hackett PH, Roach RC, Schoene RB, Harrison GL, Mills WJ Jr. Abnormal control of ventilation in high-altitude pulmonary edema. J Appl Physiol 1988; 64: 1268-1272.

12. Matsuzawa Y, Fujimoto K, Kobayashi T, et al. Blunted hypoxic ventilatory drive in subjects susceptible to highaltitude pulmonaly edema. J Appl Physiol 1989; 66: 1152-1157.

13. Selland MA, Stelzner TJ, Stevens T, Mazzeo RS, McCullough RE, Reeves JT. Pulmonary function and hypoxic ventilatory response in subjects susceptible to high-altitude pulmonary edema. Chest 1993;103: 111-116.

14. Oelz O, Maggiorini M, Ritta M, et al. Nifedipine for high altitude pulmonary oedema. Lancet 1989; ii: 1241-1244.

15. Hackett PH, Roach RC, Hartig GS, Greene ER, Levine BD. The effect of vasodilators on pulmonary hemodynamics in high altitude pulmonary edema: a comparison. Int J Sports Med 1992; 13: S68-S71.

16. Vollenweider L, Delabays A, Kleger G-R, et al. Inhaled nitric oxide for high-altitude pulmonary edema. Houston CS, Sutton JR, Coates G, eds. Burlington, Vermont, Keen City Printers inc., 1995, (Abstract) 
17. Hultgren HN, Grover RF, Hartley LH. Abnormal circulatory responses to high altitude in subjects with a previous history of high-altitude pulmonary edema. Circulation 1971; 44: 759-770.

18. Kawashima A, Kubo K, Kobayashi T, Sekiguchi M. Hemodynamic responses to acute hypoxia, hypobaria, and exercise in subjects susceptible to high-altitude pulmonary edema. J Appl Physiol 1989; 67: 1982-1989.

19. Yagi H, Yamada H, Kobayashi T, Sekiguchi M. Doppler assessment of pulmonary hypertension induced by hypoxic breathing in subjects susceptible to high altitude pulmonary edema. Am Rev Respir Dis 1990; 142: 796801.

20. Viswanathan R, Jain SK, Subramanian S, Subramanian TAV, Dua GL, Giri J. Pulmonary edema of high altitude. II. Clinical, aerohemodynamic, and biochemical studies in a group with history of pulmonary edema of high altitude. Am Rev Respir Dis 1969; 100: 334341.

21. Naeije R, Mélot C, Jejeune P. Hypoxic pulmonary vasoconstriction and high altitude pulmonary edema. Am Rev Respir Dis 1986; 134: 332-333.

22. Vachiéry J-L, McDonagh T, Moraine JJ, et al. Doppler assessment of hypoxic pulmonary vasoconstriction and susceptibility to high-altitude pulmonary oedema. Thorax 1995; 50: 22-27.

23. Sampson JB, Cymerman A, Burse RL, Maher JT, Rock $\mathrm{PB}$. Procedures for the measurement of acute mountain sickness. Aviat Space Environ Med 1983; 54: 10631073.
24. Rebuck AS, Campbell EJ. A clinical method for assessing the ventilatory response to hypoxia. Am Rev Respir Dis 1974; 109: 345-350.

25. Weil JV, Bryne-Quinn E, Sodal IE, et al. Hypoxic ventilatory drive in normal man. J Clin Invest 1970; 49: 1061-1072.

26. Read DJC. A clinical method for assessing the ventilatory response to carbon dioxide. Aust Ann Med 1966; 16: 20-32.

27. Yock PG, Popp RL. Noninvasive estimation of right ventricular systolic pressure by Doppler ultrasound in patients with tricuspid regurgitation. Circulation 1984; 70: 657-662.

28. Hatle L. Noninvasive methods of measuring pulmonary artery pressure and flow velocity. In: Chazov EI, Smirnov VN, Oganov RG eds. Cardiology, an Intemational Perspective. Vol. 2. New York, Plenum Press, 1984; pp. 783-790.

29. Hatle L, Angelsen B. In: Doppla ultrasound in cardiology: physical principles and clinical application. Philadelphia, Lea and Febiga, 1985.

30. Milledge JS, Thomas PS, Beeley JM, English JSC. Hypoxic ventilatory response and acute mountain sickness. Eur Respir J 1988; 1: 948-951.

31. Hackett PH, Rennie D, Hofmeister SE, Grover RF, Grover $\mathrm{EB}$, Reeves JT. Fluid retention and relative hypoventilation in acute mountain sickness. Respiration 1982; 43: 321-329.

32. Richalet JP, Keromes A, Dersch B, et al. Caractéristiques physiologiques des alpinistes de haute altitude. Sci Sports 1988; 3: 89-108. 